Gut, 1985, 26, 1367-1372

\title{
Abnormal responses to morphine-neostigmine in patients with undefined biliary type pain
}

\author{
I C ROBERTS-THOMSON AND J TOOULI
}

\begin{abstract}
From the Clinical Research Unit, The Walter and Eliza Hall Institute of Medical Research and the Royal Melbourne Hospital, Victoria, Australia and the Department of Surgery, Flinders University of South Australia
\end{abstract}

SUMMARY The occurrence of pain and changes in serum concentrations of liver enzymes and amylase were investigated after challenge with intramuscular morphine $(0.12 \mathrm{mg} / \mathrm{kg})$ and neostigmine $(0.012 \mathrm{mg} / \mathrm{kg})$ in 25 control subjects and 80 patients with undefined biliary type pain, both with and without prior cholecystectomy. Peak enzyme concentrations were reached at four hours after the injection of morphine-neostigmine. When compared with controls, patients who had pain after cholecystectomy and a dilated bile duct and/or spontaneous changes in liver enzymes, had a higher frequency of drug induced pain and a higher frequency of rise $(>2 \times N)$ in serum concentrations of aspartate aminotransferase (AST) and amylase; postcholecystectomy patients with pain but without bile duct dilatation, and patients with pain without prior cholecystectomy, had a higher frequency of drug induced pain but did not have a higher frequency of enzyme rise. Increases in liver enzymes after morphine-neostigmine were abolished by endoscopic sphincterotomy. Thirty three patients with a dilated bile duct and/or spontaneous changes in liver enzymes were also studied by endoscopic manometry of the sphincter of Oddi: similar frequencies of enzyme changes were observed in patients with normal manometry as in those with various manometric disorders. Increases in serum concentrations of liver enzymes after morphine-neostigmine may be explained by high biliary pressures resulting from an exaggerated motor response in the sphincter of Oddi.

The propensity of morphine to initiate or aggravate undefined biliary-type pain, particularly pain after cholecystectomy, has long been recognised. In 1936, studies by McGowan et al ${ }^{1}$ showed that morphine given subcutaneously increased intraduct pressures in patients with biliary T-tubes and that rises in intraduct pressures could be associated with abdominal pain. In 1949, Knight et $a l^{2}$ found that neostigmine could raise concentrations of serum amylase in some patients with relapsing pancreatitis and, in 1950, morphine was shown to produce some rise in serum amylase both in control subjects and in patients with various biliary and pancreatic disorders. $^{3}$

The use of morphine combined with neostigmine was first promoted by Nardi and Acosta as a provocative test in patients with abdominal pain

Address for correspondence: Dr I C Roberts-Thomson, MD, FRACP, Clinical Research Unit, Walter and Eliza Hall Institute of Medical Research, Post Office, Royal Melbourne Hospital, Victoria 3050, Australia.

Received for publication 22 February 1985 thought to be caused by inflammatory disorders of the sphincter of Oddi. ${ }^{4}$ Subsequent studies $^{5-7}$ showed that morphine alone could raise transaminase concentrations in patients with prior cholecystectomy and that patients with drug induced pain developed a higher transaminase concentration than those without pain. ${ }^{7}$ Moreover, Gregg et $a l^{8}$ found that patients with a five-fold rise in lipase after morphine-neostigmine frequently had a papilla which was difficult to cannulate at retrograde cholangiopancreatography and had operative findings consistent with papillary stenosis. These observations, however, were not corroborated by LoGiudice $e t$ al 9 wo found that enzyme responses to morphine-neostigmine were unrelated to operative findings and to basal pressure in the sphincter of Oddi as measured by endoscopic manometry.

Although the above studies show that altered responses to morphine-neostigmine do occur in some patients with undefined biliary type pain, several problems remain; these relate to the lack of 
objective criteria for classifying pain syndromes and recruitment in some studies of appropriately matched control subjects. Furthermore, there is no agreement at present as to whether the response to morphine-neostigmine will identify a subgroup of patients who will benefit from currently available forms of therapy. We describe the occurrence of pain and changes in serum concentrations of liver enzymes and amylase after intramuscular morphineneostigmine in controls and patients with biliary type pain, both with and without prior cholecystectomy. Some patients were also studied by endoscopic manometry of the sphincter of Oddi.

\section{Methods}

\section{PATIENTS}

We studied 80 patients with abdominal pain suggestive of biliary disease. Some had discrete episodes of severe pain separated by intervals of several months while others had milder but more frequent pains, occurring almost daily. Pain was located in the right hypochondrium or epigastrium, radiated into the back, sometimes fluctuated in severity and could last for up to several hours before settling either spontaneously or with analgesic drugs. More severe symptoms were usually accompanied by nausea and vomiting. All patients had undergone many investigations without the discovery of any cause for their symptoms and most had been treated with antispasmodic drugs, tranquilisers and antidepressant drugs without sustained improvement in symptoms. The 80 patients were classified into three groups. Group I comprised 40 with prior cholecystectomy who had a dilated bile duct on retrograde cholangiography $(>12 \mathrm{~mm}$ in diameter when adjusted for magnification) and/or transient changes in liver function tests after spontaneous episodes of pain, usually a rise in the serum level of aspartate aminotransferase (AST). Group II comprised 20 patients with typical biliary symptoms after cholecystectomy in whom retrograde cholangiography was normal and who had normal liver function tests after severe episodes of pain. Group III comprised 20 patients without prior cholecystectomy in whom an oral cholecystogram, biliary ultrasound study and upper gastrointestinal endoscopy were normal. Ten of these patients were also studied by microscopy of duodenal bile after an intravenous injection of cholecystokinin octapeptide (CCK-OP); no biliary crystals were seen.

There were two control groups; group A comprised 15 patients without pain at least two years after cholecystectomy and group B comprised 10 individuals without pain who had not had previous biliary surgery. The sex ratio, mean age, operative findings and mean interval since cholecystectomy for patient and control groups are shown in Table 1.

The morphine-neostigmine test was carried out after an overnight fast. Patients received an intramuscular injection of normal saline at $0800 \mathrm{~h}$ and, at $0900 \mathrm{~h}$, were given an intramuscular injection of morphine $(0.12 \mathrm{mg} / \mathrm{kg})$ and neostigmine $(0.012$ $\mathrm{mg} / \mathrm{kg}$ ). Blood was taken for serum concentrations of AST, alanine aminotransferase (ALT), glutamyl aminotransferase (GGT), alkaline phosphatase (ALP), bilirubin and amylase at 0800 and hourly for five hours. Food and fluids were withheld for the duration of the study. Pain was assessed in all patients by one nursing sister and confirmed by one author (IRT) and, if pain developed, patients were encouraged to tolerate symptoms for at least 10 minutes. If severe pain ensured, the effect of the injection was reversed, at least in part, by the intravenous injection of naloxone $(0.4 \mathrm{mg})$ and atropine $(0.4 \mathrm{mg})$. Patients who required naloxone and atropine were classified as having severe pain and the remainder as having no pain or mild pain. Four patients who had pain and rise in AST and amylase $(>2 \times N)$ after morphine-neostigmine had a second study six to 18 months after treatment by endoscopic sphincterotomy. Liver function tests

Table 1 Sex, mean age, operative findings at the time of biliary surgery and mean interval since cholecystectomy in groups I-III and control subjects

\begin{tabular}{|c|c|c|c|c|c|c|c|}
\hline & \multirow[b]{2}{*}{ No } & \multirow[b]{2}{*}{$\begin{array}{l}\text { Women } \\
\text { (no) }\end{array}$} & \multirow[b]{2}{*}{$\begin{array}{l}\text { Mean } \\
\text { age }\end{array}$} & \multicolumn{3}{|c|}{ Operative findings } & \multirow{2}{*}{$\begin{array}{l}\text { Mean interval } \\
\text { since } \\
\text { cholecyst- } \\
\text { ectomy (yr) }\end{array}$} \\
\hline & & & & $\begin{array}{l}\text { Gall } \\
\text { bladder } \\
\text { stones }\end{array}$ & $\begin{array}{l}\text { Normal } \\
\text { gall } \\
\text { bladder }\end{array}$ & $\begin{array}{l}\text { No } \\
\text { record }\end{array}$ & \\
\hline Group I & 40 & 37 & 52 & 26 & 10 & 4 & 7 \\
\hline Group II & 20 & 19 & 44 & 9 & 9 & 2 & 8 \\
\hline Group III & 20 & 16 & 43 & NA & NA & NA & NA \\
\hline Control A & 15 & 12 & 55 & 13 & 0 & 2 & 11 \\
\hline Control B & 10 & 5 & 43 & NA & NA & NA & NA \\
\hline
\end{tabular}

NA = not applicable 
were carried out by autoanalyser (Technicon SMAC); the upper limits of normal were $43 \mathrm{IU} / \mathrm{l}$ for AST, $55 \mathrm{IU} / \mathrm{l}$ for ALT, $50 \mathrm{IU} / \mathrm{l}$ for GGT, $90 \mathrm{IU} / \mathrm{l}$ for ALP and $20 \mu \mathrm{mol} / \mathrm{l}$ for bilirubin. Serum amylase was determined by a discrete analyser (ASTRA 8); the upper limit of normal was 350 IU/l. Rise in the serum level of enzymes to two-fold or more above the upper limit of normal was defined as abnormal and has been expressed as $>2 \times N$.

Manometric records from the sphincter of Oddi were obtained at duodenal endoscopy using a triple lumen catheter system of low compliance. The technique of endoscopic biliary manometry and results in control subjects and patients with suspected biliary dyskinesia have been described in detail in a previous report. ${ }^{10}$ Of the 33 patients from group I who were studied by endoscopic manometry, seven had normal manometric records, 10 had fixed structural stenosis with a rise in the sphincter basal pressure $(>41 \mathrm{~mm} \mathrm{Hg})$ and 16 were classified as having biliary dyskinesia with an excess of retrograde sphincter sequences $(>50 \%)$, rapid phasic contractions $(>7 / \mathrm{min})$ and/or an abnormal response to intravenous CCK-OP $(20 \mathrm{ng} / \mathrm{kg})$ with absence of inhibition of phasic contractions.

\section{STATISTICS}

The frequency of pain and increases $(>2 \times N)$ in serum concentrations of AST and amylase in patient and control groups was compared by $\chi^{2}$ while enzyme levels in patient and control groups were compared using the Wilcoxon's rank test.

\section{Results}

PAIN

Pain was not reported by any subject for one hour after the injection of normal saline. After morphineneostigmine, however, two controls reported mild pain and 65 patients had either mild or severe pain, identical in site and quality to spontaneous attacks outside hospital. Pain began after 15 to 60 minutes, persisted for up to two hours and was sometimes accompanied by nausea, vomiting, and restlessness. The severity of pain was reduced after five to $\mathbf{1 5}$ minutes by the intravenous injection of naloxone and atropine but severe pain recurred in 12 patients and was treated with further intravenous injections of naloxone. As shown in Table 2, mild or severe pain was more frequent in groups I and II than in control group A $(\mathrm{p}<0.001)$ and in Group III when compared to control group $B(p<0.02)$. In addition, severe pain (requiring drug therapy) was more frequent in groups $I(p<0.005)$ and II $(p<0.001)$ with prior cholecystectomy than in patients in group III who had not had biliary surgery.
Table 2 Numbers of patients without pain or with mild or severe pain after the injection of morphine-neostigmine.

\begin{tabular}{lcccc}
\hline & No & $\begin{array}{l}\text { No } \\
\text { pain }\end{array}$ & $\begin{array}{l}\text { Mild } \\
\text { pain }\end{array}$ & $\begin{array}{l}\text { Severe } \\
\text { pain }\end{array}$ \\
\hline Group I & 40 & 6 & 16 & 18 \\
Group II & 20 & 0 & 7 & 13 \\
Group III & 20 & 9 & 10 & 1 \\
Control A & 15 & 14 & 1 & 0 \\
Control B & 10 & 9 & 1 & 0 \\
\hline
\end{tabular}

DRUG INDUCED CHANGES IN SERUM ENZYMES

Some postcholecystectomy patients, particularly those in group I, showed marked rises in serum concentrations of AST and ALT which reached a maximum at four hours after the injection of morphine-neostigmine; a typical example is shown in Figure 1. The highest recorded level of AST was $679 \mathrm{IU} / \mathrm{l}(16 \times \mathrm{N})$ and the highest level of ALT was $420 \mathrm{IU} / 1(10 \times \mathrm{N})$. In patients showing changes in liver enzymes, the ratio of peak: upper normal levels, was in the following order AST>ALT$>$ GGT $>$ ALP. All patients who showed rises of ALT, GGT or ALP had elevation of AST.

Numbers of patients showing rises $(>2 \times N)$ in serum levels of various liver enzymes and amylase after morphine-neostigmine are shown in Table 3. Patients in group I had a higher frequency of rise in AST $(p<0.02)$ and amylase $(p<0.05)$ than those in control group A. Similar frequencies of enzyme rise were, however, observed in group II and control group A. Patients in group III did not show increases in liver enzymes and the frequency of rise

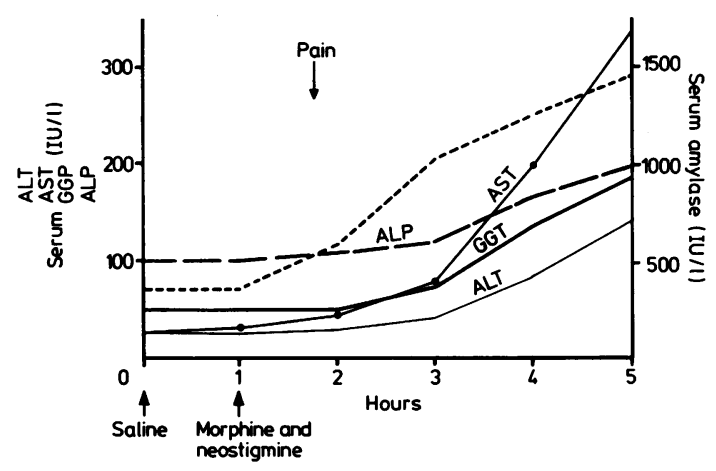

Fig. 1 Changes in serum concentrations of $A S T, A L T$, GGT, ALP and amylase (interrupted line) after morphine-neostigmine in one patient with biliary-type pain, a dilated bile duct and spontaneous changes in serum concentrations of liver enzymes. 
Table 3 Numbers of patients with peak liver enzyme and amylase concentrations $>2 \times N$ in groups I-III and controls

\begin{tabular}{lcccccc}
\hline & & $\begin{array}{c}A S T \\
>2 \times N\end{array}$ & $\begin{array}{l}A L T \\
>2 \times N\end{array}$ & $\begin{array}{l}G G T \\
>2 \times N\end{array}$ & $\begin{array}{l}A L P \\
>2 \times N\end{array}$ & $\begin{array}{l}\text { Amylase } \\
>2 \times N\end{array}$ \\
\hline Group I & 40 & 15 & 8 & 7 & 1 & 13 \\
Group II & 20 & 4 & 1 & 1 & 0 & 4 \\
Group III & 20 & 0 & 0 & 0 & 0 & 11 \\
Control A & 15 & 1 & 1 & 1 & 0 & 1 \\
Control B & 10 & 0 & 0 & 0 & 0 & 2
\end{tabular}

The same individual in control group A showed rises in AST, ALT, GGT and amylase.

in amylase was not higher than in control group B.

Mean values $( \pm \mathrm{SE})$ for liver enzymes and serum amylase in groups I and II and control group A are shown in Figure 2 and for group III and control group B in Figure 3. When compared with control group A, patients in group I showed significantly higher concentrations of AST at three hours $(\mathrm{p}<0.05)$ and four hours $(\mathrm{p}<0.02)$ and significantly higher concentrations of ALT at four hours $(p<0.05)$. Serum concentrations of amylase were significantly higher at three hours $(p<0.05)$ but differences at four hours were not statistically significant $(0 \cdot 05<p<0 \cdot 1)$. Patients in group II had similar concentrations of liver enzymes and amylase to those in control group A. Although higher mean concentrations of amylase were recorded in group III than in control group B, differences between groups did not reach statistical significance $(0.05<\mathrm{p}<0.1)$.

All patients who had rises $(>2 \times N)$ in serum concentrations of AST after morphine-neostigmine had either mild or severe pain whereas a rise in amylase occurred in the absence of pain in two patients in group I, five in group III and two in control group B. Six of 12 patients with changes in liver enzymes after spontaneous episodes of pain showed increases in AST levels after morphineneostigmine.

\section{STUDIES AFTER SPHINCTEROTOMY}

Four patients who had pain and rises in serum concentrations of AST and amylase after morphineneostigmine had a second study, six to 18 months after endoscopic sphincterotomy. During the second study, two patients were free of pain while two had a marked reduction in the severity of symptoms with only lower abdominal cramps and nausea. Serum concentrations of liver enzymes remained within the normal range but serum amylase concentrations were mildly raised in two of four patients. Mean peak amylase levels were $2749 \mathrm{IU} / \mathrm{l}$ before sphincterotomy and $713 \mathrm{IU} / \mathrm{l}$ after sphincterotomy.
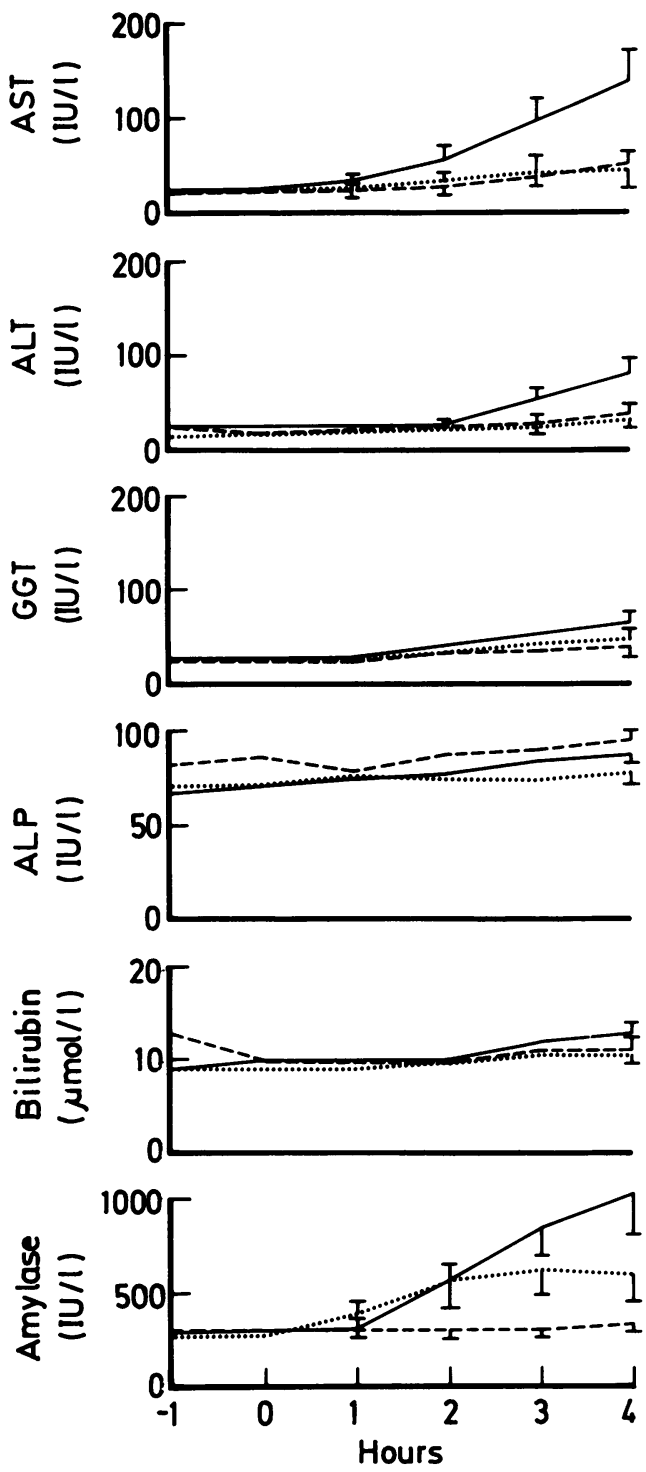

Fig. 2 Mean serum concentrations ( $\pm S E$ ) of $A S T, A L T$, $G G T, A L P$, bilirubin and amylase after

morphine-neostigmine in patients in groups I (continuous line), II (interrupted line) and control group A (dotted line).

\section{RELATIONSHIP OF ENZYME CHANGES TO} MANOMETRIC FINDINGS

A rise in AST $(>2 \times N)$ was observed in two of seven patients with normal manometry, three of 10 with fixed structural stenosis and four of 16 with biliary dyskinesia. Similarly, a rise in amylase $(>2 \times N)$ was observed in two of seven patients with normal 

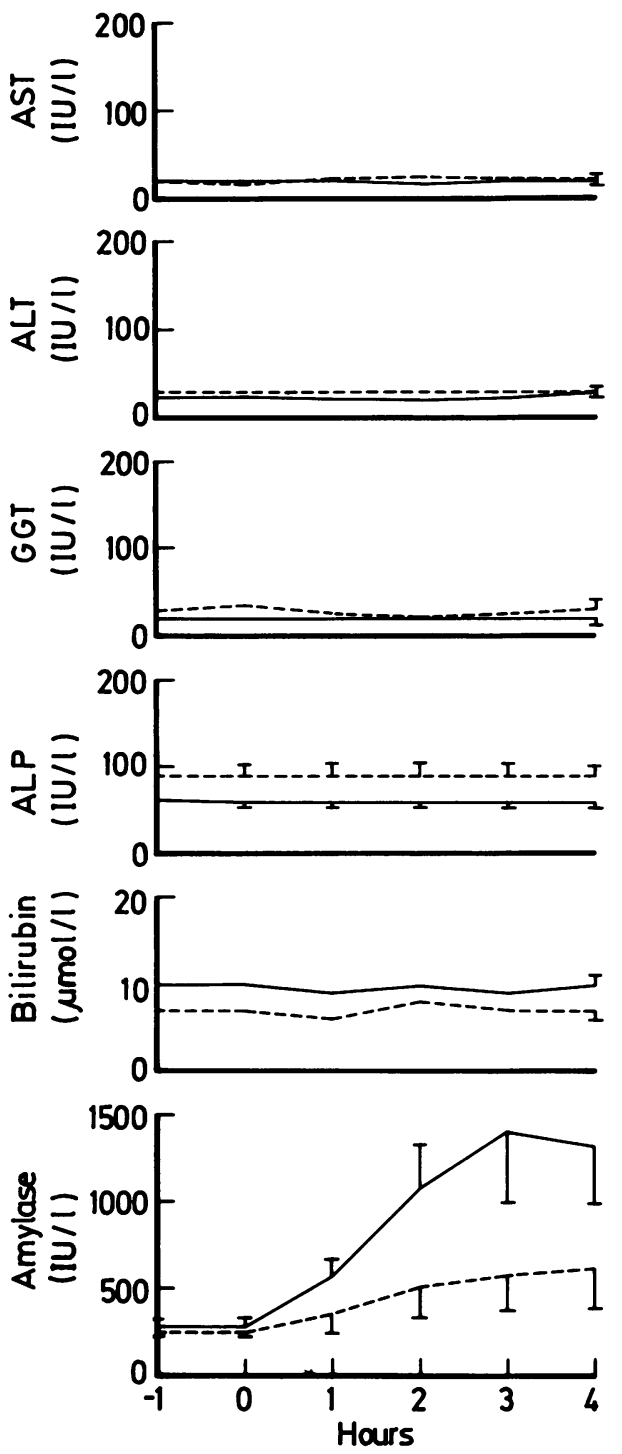

Fig. 3 Mean serum concentrations ( $\pm S E$ ) of $A S T, A L T$, $G G T, A L P$, bilirubin and amylase after morphine-neostigmine in patients in groups III (continuous line) and control group $B$ (interrupted line).

manometry, three of 10 with fixed structural stenosis and five of 16 with biliary dyskinesia.

\section{Discussion}

Results from this study show that in patients with undefined biliary pain after cholecystectomy, the injection of morphine-neostigmine reproduces the pain and, when bile duct dilation and/or spontaneous changes in liver enzymes are present, there is a high frequency of rises in serum concentrations of AST and amylase. In contrast, in patients with similar pain but without prior cholecystectomy, there is a high frequency of pain (although this is usually mild), but increases in serum concentrations of liver enzymes and amylase are not more frequent than in controls.

Although several studies have focused on the degree of rise in serum amylase or lipase after morphine-neostigmine,${ }^{389}$ we have found that substantial increases in serum amylase can occur in control subjects and that two patients had increases in serum amylase in the absence of drug-induced pain. Increases in serum concentrations of AST, however, were always associated with either mild or severe pain and were observed in only one of 15 controls. A rise in the AST concentration appears to be a more useful marker of altered responsiveness to morphine-neostigmine and a level $>2 \times \mathbf{N}$ after four hours would permit categorisation of patients for future studies.

Increased serum concentrations of liver enzymes after morphine-neostigmine can be explained by the generation of high intrabiliary pressures, particularly as enzyme changes were absent in patients with a gall bladder in situ and were abolished by endoscopic sphincterotomy. Similarly raised concentrations of serum amylase are presumably caused by raised pressures in pancreatic ducts which divert amylase and other pancreatic enzymes into the circulation. An alternative explanation, that abnormalities in liver and pancreatic cells allow for minor increases in intraduct pressures to cause leakage of enzymes into the circulation, seems unlikely.

We confirmed in this study that pain develops after morphine-neostigmine in predisposed subjects but the mechanisms are unclear. Possible explanations include duct distension due to high intraduct pressures, abnormally rapid rises in intraduct pressures, low pain thresholds for duct distension and altered motor activity in areas of the gastrointestinal tract apart from the sphincter of Oddi. While there may be variation from case to case in the importance of the above mechanisms, several observations emphasise the role of the biliary tract in the generation of pain after morphine-neostigmine. These include a marked amelioration of druginduced pain after endoscopic sphincterotomy, absence of severe pain in most patients with a gall bladder in situ and the association of drug induced pain with increases in serum concentrations of liver enzymes in some patients. Whether spontaneous episodes of pain have a similar explanation remains 
controversial although all patients described drug induced pain as being identical to spontaneous attacks outside of hospital and, in some patients, spontaneous attacks were associated with changes in liver enzymes.

In this study, increases in serum concentrations of AST and amylase after morphine-neostigmine were independent of motor activity in the sphincter of Oddi in patients with a dilated bile duct and/or spontaneous changes in serum concentrations of liver enzymes. A study by LoGiudice et al ${ }^{9}$ also showed no correlation between amylase and lipase rises after morphine-neostigmine and basal pressure in the sphincter of Oddi as assessed by endoscopic manometry. It seems likely, therefore, that factors influencing motor responses to morphineneostigmine are not related either to those which determine basal motility in the sphincter of Oddi or to motor responses to the intravenous injection of CCK-OP.

Whether the enzyme changes after morphineneostigmine could be reproduced by morphine alone has not been addressed in this or previous studies. The absence of amylase rise in most patients given only morphine, ${ }^{7}$ however, raises the possibility that neostigmine facilitates an increase in serum concentrations of pancreatic enzymes, presumably by increasing the volume of pancreatic secretions.

The direct demonstration of an augmented motor response to morphine should now be possible with endoscopic manometry, perhaps corroborated by results from prolonged monitoring of intrabiliary pressures. ${ }^{11}$ This effect, if confirmed, could be attributed to changes in the production of endogenous opioids and/or distribution of opioid receptors which influence motor activity in the sphincter of Oddi probably via several mechanisms including changes in the excitability of inhibitory enteric neurones. $^{12}$

We are grateful to Dr I R Mackay and Dr D J B St John for assistance with the project and for helpful criticism of the manuscript and to Dr D G Campbell for carrying out the serum biochemistry. Endoscopic biliary manometry was done with help from $\mathrm{Mr} \mathrm{J}$ Lee.

\section{References}

1 McGowan JM, Butsch WL, Walters W. Pressure in the common bile duct of man: its relation to pain following cholecystectomy. JAMA 1936; 106: 2227-30.

2 Knight WA, Muether RO, Sommer AJ. Chronic recurrent pancreatitis. Gastroenterology 1949; 12: 34 48.

3 Burke JO, Plummer K, Bradford S. Serum amylase response to morphine, mecholyl and secretin as a test of pancreatic function. Gastroenterology 1950; 15: 699-707.

4 Nardi GL, Acosta JM. Papillitis as a cause of pancreatitis and abdominal pain: role of evocative test, operative pancreatography and histologic evaluation. Ann Surg 1966; 164: 611-9.

5 Mossberg SM, Bloom A, Berkowitz J, Ross G. Serum enzyme activities following morphine. Arch Intern Med 1962; 109: 105-13.

6 Laursen T, Schmidt A. Increase in serum GPT and serum LDH after administration of morphine to patients suffering from bile-duct dyskinesia. Scand $J$ Clin Lab Invest 1966; 92: suppl: 175-7.

7 Holtzer JD, Hulst SGTh. Confirmation of postcholecystectomy biliary dyskinesia by elevation of serum transaminases (GOT and GPT) after injection of morphine. Acta Med Scand 1973; 194: 221-4.

8 Gregg JA, Taddeo AE, Milano AF et al. Duodenoscopy and endoscopic pancreatography in patients with positive morphine prostigmine tests. Am J Surg 1977; 134: 318-21.

9 LoGiudice JA, Greenen JE, Hogan WJ, Dodds WJ. Efficacy of morphine-prostigmine test for evaluating patients with suspected papillary stenosis. Dig Dis Sci 1979; 24: 455-8.

10 Toouli J, Roberts-Thomson IC, Dent J, Lee J. Manometric disorders in patients with suspected sphincter of Oddi dysfunction. Gastroenterology 1985; 88: 1243-50.

11 Tanaka M, Ikeda S, Nakayama F. Continuous measurement of common bile duct pressure with an indwelling microtransducer catheter introduced by duodenoscopy: new diagnostic aid for postcholecystectomy dyskinesia - a preliminary report. Gastrointest Endoscopy 1983; 29: 83-8.

12 Wood JD. Intracellular study of effects of morphine on electrical activity of myenteric neurons in cat small intestine. Gastroenterology 1980; 79: 1222-30. 